\title{
The Effect of Target Repetition on Semantic Priming in a Three-Target RSVP Task
}

\author{
Karen Murphy ${ }^{1} \&$ Casey Bloom ${ }^{2}$ \\ ${ }^{1}$ Menzies Health Institute Queensland and School of Applied Psychology, Griffith University, Gold Coast, \\ Queensland 4222, Australia \\ ${ }^{2}$ School of Applied Psychology, Griffith University, Gold Coast, Queensland 4222, Australia \\ Correspondence: Karen Murphy, School of Applied Psychology, Gold Coast campus, Griffith University, Gold \\ Coast, Queensland 4222, Australia. Tel: 61-75-678-8952. E-mail: k.murphy@griffith.edu.au
}

Received: June 22, 2015 Accepted: July 14, 2015 Online Published: August 12, 2015

doi:10.5539/ijps.v7n3p76 URL: http://dx.doi.org/10.5539/ijps.v7n3p76

\begin{abstract}
This study used a rapid serial visual presentation task to examine the impact of target relatedness on report accuracy. In this task participants were shown a series of briefly presented words and were required to identify the three colored target words from the stream of distractor words. In two experiments participants either recalled the three targets words from memory at the end of each trial or recognized the targets from a list of all possible targets. The first target shown on each trial was unrelated to the second or third target. The second and third targets within each stream were semantically related (e.g., dog and cat) on half the trials and unrelated on the other half the trials (e.g., table and cat). The effect of the second and third targets sharing a relationship was examined for Target 3 accuracy. Target 3 accuracy was greater if it was preceded by a related Target 2 , compared to when Targets 2 and 3 were unrelated. This shows a semantic priming effect (facilitation effect) for Target 3 accuracy, when the both Target 2 and 3 were identified. In contrast, when Target 2 was missed or incorrectly reported there was no difference in accuracy for related or unrelated target contexts (no priming or facilitation effect for Target 3). These semantic priming effects were evident in the recall and recognition tasks in Experiment 1 and 2. This study shows that a target presented during a rapid serial visual presentation task must be consciously processed to facilitate the report of a subsequently presented target word.
\end{abstract}

Keywords: rapid serial visual presentation, attentional blink, semantic priming, target repetition, attention

\section{Introduction}

The term attention refers to integrated neural processes used to select a given perceptual input from competing inputs within the environment (Shapiro, Arnell, \& Raymond, 1997). The limitations in human's abilities to process sequential visual inputs across time have been investigated using the rapid serial visual presentation (RSVP) technique (e.g., Broadbent \& Broadbent, 1987; Chun \& Potter, 1995; Maki, Frigen, \& Paulson, 1997; Raymond, Shapiro, \& Arnell, 1992). In a typical RSVP task, a series of stimuli (letters, digits, pictures or words) are presented at rates of about 10 to 12 items per second, and participants are required to report one or more targets from the stream. Targets are differentiated from distractors within the RSVP stream on the basis of luminance, colour, case or category (Chun, 1997). Within the RSVP task, temporal attention is examined by manipulating the time interval between the targets. That is, the stimulus onset asynchrony (SOA) (time interval between the onset one target and the onset of the next target) is varied systematically during the task.

An early study of temporal attention was conducted by Broadbent and Broadbent (1987). These researchers found that when participants were required to identify two targets within a RSVP stream, the processing of the first target (T1) interfered with the processing of a second target (T2). That is, when T2 appeared at SOAs of 200 to $500 \mathrm{msec}$ after the presentation of T1, T2 response accuracy was impaired compared to longer SOAs between targets. This T2 processing deficit is referred to as the Attentional Blink (Raymond et al., 1992), and generally T2 report is most impaired when the T1-T2 SOA is between 200 to 300 milliseconds.

The attentional blink has been shown to occur when targets were letters (Shapiro, Driver, Ward, \& Sorensen, 1997; Chun \& Potter, 1995), words (Broadbent \& Broadbent, 1997; Shapiro, Driver, et al., 1997; Maki et al., 2003), and pictures (Dux \& Harris, 2007). It has also been shown that the attentional blink occurs for both recall 
and recognition tasks (Maki, Couture, Frigen, \& Lien, 1997). The current study used a three-target RSVP task to examine if target repetition during the response stage influences Target 3 accuracy in this paradigm. A further aim of the study was to examine the impact of a related context between Target 2 and 3 on report Target 3 accuracy.

Priming refers to the observation that people respond faster to a target word (e.g., cat) when it is preceded by a related prime (e.g., dog) than when it is preceded by an unrelated prime word (e.g., table) (Meyer \& Schvaneveldt, 1971; Schvaneveldt \& Meyer, 1973; Meyer, Schvaneveldt, \& Ruddy, 1975; Neely, 1991). Most research examining priming effects during the attentional blink has manipulated the context between two target words within the RSVP stream. For example, in an RSVP task, priming is typically assessed by comparing T2 accuracy in the condition where it follows a related T1 compared to when it follows an unrelated T1. Numerous studies have shown that a related target context reduces the magnitude of the attentional blink (i.e., assists with the report of T2) and is therefore indicative of a priming effect in RSVP tasks (Juola, Duvuru, \& Peterson, 2000; Maki, Frigen et al., 1997; Murphy \& Hunt, 2013; Nyawata \& Murphy, 2013; Shapiro, Driver et al., 1997). Research has also shown that priming can occur even when a target has not been consciously identified during the attentional blink period (SOA between T1 and T2 is 200 to 300 msec) (Luck, Vogel, \& Shapiro, 1996; Martens, Wolters, \& van Raamsdonk, 2002; Rolke, Heil, Streb, \& Henninghausen, 2001; Shapiro, Driver et al., 1997; Vogel et al., 1998). Thus priming has been found to occur when one target consciously or unconsciously primes the presentation of a second target.

Shapiro, Driver et al. (1997, Experiment 2) used a three-target RSVP task to ascertain if a missed T2 could prime a related third target (T3). For each trial, participants were required to identify the three targets shown in a RSVP stream of distractor words. T2 was presented after T1, during the time interval where the attentional blink should be maximal (at an SOA of $270 \mathrm{msec}$ from $\mathrm{T} 1$ onset), and $\mathrm{T} 3$ was presented at a time period beyond the attentional blink (at an SOA of $540 \mathrm{msec}$ following T1 onset). For half the trials T2 and T3 were related and on the other half the trials T2 and T3 were unrelated. T1 was not related to T2 or T3. Shapiro, Driver et al. (1997) found that priming occurred for trials in which T2 was identified or missed. That is, even when T2 was not identified, T2 primed T3 (facilitated the identification of T3) when the two words were related but not when T2 and $\mathrm{T} 3$ were unrelated. Thus regardless of $\mathrm{T} 2$ being reported or missed due to an attentional blink, a related T2-T3 context resulted in priming.

Although Shapiro, Driver et al.'s (1997) findings provide a significant contribution to understanding the mechanisms underlying the attentional blink, there are some aspects of the task that might have affected the results. For example, limited pools of distractor and target items were used in the task, with each target word being presented 24 times during the experiment and an additional 312 times during response. Consequently, it is possible that repetition priming might have impacted on the results of the study. Repetition priming refers to improvements in the speed or accuracy of word identification as a result of presenting items multiple times during an experiment (Forster \& Davis, 1984). For example, Bodner and Masson (2001) found that when the target word repetition was high during an experiment, this resulted in greater identification accuracy than when there was less repetition.

As semantic priming produces a performance advantage for related trials (Neely, 1991), and repetition priming produces a performance advantage for repeated items (Durgunoglu, 1988; Forster \& Davis, 1984; Rueckl, 1990), it would be expected that repeated word presentation should result in larger semantic priming effects. However, studies have demonstrated that the repeated presentation of primes actually eliminates semantic priming effects in lexical decision tasks (Neely et al., 1998; Pitzer \& Dagenbach, 2001). A study investigating prime repetition and semantic priming presented participants with a series of letter strings that consisted of two prime words, followed by the presentation of a target word (Pitzer \& Dagenbach, 2001). The prime and target context was also varied. The two primes were repeated and related to the target, or repeated and unrelated to the target, or different and only one prime was related to the target. Results revealed that when prime words were repeated, there was no difference between the response times in the related and unrelated word conditions. That is, prime repetition eliminated the semantic priming effects.

Another factor that might have impacted in the results of Shapiro, Driver et al. (1997) is the semantic satiation effect. Studies have reported the subjective loss of meaning of a word (semantic satiation) through prolonged exposure to and repetition of a word (e.g., Smith, 1984; Smith \& Klein, 1990; Wertheimer \& Gillis, 1958). For example, Smith (1984) used a category membership task and required participants pronounced the category name (e.g., fruit) 3 or 30 times as it appeared on the computer screen. After the final repetition, a target word (that was either related or unrelated to the category name e.g., apple or hawk) appeared on the screen. Participants had to decide if the target word was a member of the pronounced category. When the target was a 
member of the repeated category, response times increased with the number of repetitions suggesting that word repetition decreases the availability of semantic information about that word.

Therefore, word repetition during an experiment can result in the reduction or elimination of semantic priming effects via either repetition priming or semantic satiation effects. This has implications for the results obtained by Shapiro, Driver et al. (1997), as they repeatedly presented targets within the RSVP task and also during the response stage of the task. Consequently, this target repetition may have reduced the magnitude of the priming effects observed in their study. To date it appears that the issue of target repetition during the response stage of a RSVP task has not been investigated in relation to semantic priming effects. The current study examined this issue by assessing semantic priming effects in a three-target RSVP task with recall and recognition response tasks.

\section{Experiment 1}

Using a three-target RSVP task Shapiro, Driver et al. (1997) found semantic priming from T2 to T3, regardless of whether T2 was reported correctly or missed (blinked). However, as mentioned previously it is possible that the extensive target repetition during their RSVP task might have reduced the magnitude of the semantic priming effects observed in their study. As the majority of word repetition occurred during the response stage of the Shapiro, Driver et al. (1997) study, the current study focused on this aspect of the task design.The impact of repeated target presentation during the response stage was investigated by using recall and recognition response modalities in a three-target RSVP task. In the recognition task, participants were provided with a printed list of all possible target words at the end of each trial and asked to identify all three targets in order of presentation. In the recall condition, there was no target repetition during response, as participants were required to write down each of the target words in order of presentation. Therefore by comparing the magnitude of the priming effects for T3 accuracy for the recall and recognition tasks this study examined if the increased repetition effects in the recognition task (i.e., repetition during response) had an impact on performance when compared to the recall task (i.e., no repetition during response).

Based on Shapiro, Driver et al. (1997), it was predicted that priming would occur for both recall and recognition tasks regardless of whether T2 was correctly or incorrectly reported. Moreover, if semantic priming was affected by target repetition, then in the current study the magnitude of the priming effects should be greater for T3 accuracy in the recall than the recognition task. That is, the reduced target repetition at the response phase in the recall compared to the recognition task should facilitate greater semantic priming in that task.

\subsection{Method}

\subsubsection{Participants}

Participants were 26 first-year psychology students (19 females), aged between 17 and 48 years $(M=26.8$ years, $S D=9.26$ ), who voluntarily completed this study in return for course credit. All participants were native English speakers, with normal or corrected to normal visual acuity and normal colour vision (Ishihara, 1994).

\subsubsection{Stimuli}

Target and distractor words were taken from Shapiro, Driver et al. (1997). A total of 26 word triplets served as the set of three target words (T1, T2 and T3). The target words ranged from three to six letters in length. Two T2-T3 context conditions were created, such that these two targets were either related or unrelated. The 13 T2-T3 word pairs in the related condition were related by semantic category membership and word association (e.g., day and night). The unrelated word pairs were created by reassigning the word pairs to produce a list where $\mathrm{T} 2$ and $\mathrm{T} 3$ were neither semantically nor associatively related (e.g., doctor and night). For each trial T1 was randomly selected from the set of $13 \mathrm{~T} 1$ words. $\mathrm{T} 1$ was neither semantically nor associatively related to $\mathrm{T} 2$ or $\mathrm{T} 3$

\subsubsection{Trial Structure}

Each trial commenced with a centrally located fixation cross (black font) for $180 \mathrm{~ms}$, followed by a stream of 15-23 words, shown on a mid-grey background on the computer screen. For each trial, words were presented successively in the centre of the screen for $70 \mathrm{msec}$ each, with a $20 \mathrm{msec}$ blank interval between each word. Although these word display presentation times differed to those used by Shapiro, Driver et al. (1997), lab pilot studies using these display times produced task accuracy comparable to this previous study and were therefore used in this experiment. All uppercase words appeared on the screen in a black font except for T1, T2, and T3, which appeared in white, red and yellow font respectively. This allowed the targets to be differentiated from the distractor words. The $270 \mathrm{~ms}$ SOA between T1 and T2 placed T2 in the depth of the attentional blink, while the interval between $\mathrm{T} 1$ and $\mathrm{T} 3$ placed T3 in a position beyond the attentional blink (SOA of 540ms). To minimise primacy and recency effects in short-term memory, the first 7 to 15 words in each trial were distractors and the 
last two words in each trial were also distractors.

\subsubsection{Apparatus}

The experiment was run on a Dell 2.66 GHz Pentium 4 PC with a Dell Ultraflat colour monitor and the trials were presented using the DMDX display system (Forster \& Forster, 2003). Participants completed the experiment in a small room with low illumination and were seated $42 \mathrm{~cm}$ away from the screen. At this viewing distance, each word subtended approximately $0.55^{\circ}$ of visual angle high, with three, four, five and six letter words subtending $1.09^{\circ}, 1.64^{\circ}, 2.18^{\circ}$ and $2.73^{\circ}$ of visual angle wide respectively.

\subsubsection{Procedure}

The experiment had ethical clearance from the University Human Ethics committee and participants provided written informed consent prior to commencing the task. Prior to the RSVP task participants were presented with written onscreen instructions and they were also verbally explained the task instructions. Participants were randomly allocated to the recall task group or the recognition task group. Both groups completed the same RSVP task with the only variation being the type of response made by participants. Details of response requirements for the recall and recognition task are provided below.

Participants took approximately 60 minutes to complete the task. During the 40 practice trials, participants were asked to report each type of target alone for 10 trials and then to report all three target words together for an additional 10 trials. The practice trials consisted of an equal number of related and unrelated T2-T3 pairs. Each participant completed 208 experimental trials which were presented in four blocks of 52 trials. A rest break was scheduled between each block to minimize fatigue effects. The 208 trials were presented in a random order for each participant and progression between trials was initiated by the participant pressing the space bar when they were ready. For 104 of the trials T2-T3 were related and for 104 trials T2-T3 were not related. Each of the 13 related T2 and T3 word pairs were presented eight times to create 104 related trials, and each of the T3 words was combined with eight different unrelated T2 words to produce 104 unrelated trials. At the end of each trial, participants were prompted to write down the target words in order (recall group) or number target words in order of presentation (recognition group).

The participants in the recall group were asked to record the target words in order of presentation on the notepad provided. Each trial used a new page of the notepad for their response and the page numbers corresponding to the trial numbers were displayed on the bottom of each page. Participants in the recognition group were provided with a printed list of all the T1, T2, and T3 words that were used in the experiment. Words were listed in alphabetical order and participants were asked to pick out and number to target words in order or presentation (e.g., place the numbers 1, 2, and 3 next to the targets presented on each trial). A new list of all possible target words was used for each trial and the corresponding trial number was noted on each list.

\subsection{Results and Discussion}

To ensure there was no difference in T1 accuracy between the related and unrelated target (T2-T3) contexts for both the recall and recognition groups a 2 (response group: recall vs. recognition) x 2 (T2-T3 context: related or unrelated) mixed factorial ANOVA was used. Relevant descriptive statistics are presented in Table 1. T1 accuracy did not differ between the two groups, $F(1,24)=0.05, p=.83, \eta_{\mathrm{p}}{ }^{2}=.002$, or the T2-T3 target contexts, $F(1,24)=1.55, p=.23, \eta_{\mathrm{p}}{ }^{2}=.05$. The interaction between task and target context was not significant, $F(1,24)=$ $0.01, p=.98, \eta_{\mathrm{p}}{ }^{2}=.001$. Therefore, $\mathrm{T} 1$ accuracy was unaffected by a related target context.

Table 1. Mean percent correct for T1 (SD) for Experiment 1 and 2 for the related and unrelated T2-T3 conditions for the recall and recognition group

\begin{tabular}{|c|c|c|c|c|}
\hline & \multicolumn{2}{|c|}{ Recall Group } & \multicolumn{2}{|c|}{ Recognition Group } \\
\hline & T2-T3 Related & T2-T3 Unrelated & T2-T3 Related & T2-T3 Unrelated \\
\hline & Mean \% (SD) & Mean \% (SD) & Mean \% (SD) & Mean \% (SD) \\
\hline Experiment $1 \mathrm{~T} 1$ & $95.12(6.04)$ & $95.43(3.15)$ & $95.81(3.45)$ & $96.15(2.98)$ \\
\hline Experiment $2 \mathrm{~T} 1$ & $90.98(5.23)$ & $87.94(13.35)$ & $90.09(6.43)$ & $88.02(12.69)$ \\
\hline
\end{tabular}

A 2 (response group: recall vs. recognition) x 2 (T2-T3 context: related or unrelated) x 2 (T2 performance: 
correct or incorrect) mixed factorial ANOVA was used to analyse the T3 accuracy data from all trials where T1 was correct.

There was no evidence of response group affecting T3 performance, as the main effect of group, $F(1,24)=1.08$, $p=.31, \eta_{\mathrm{p}}{ }^{2}=.04$, the group by target context interaction, $F(1,24)=3.31, p=.08, \eta_{\mathrm{p}}{ }^{2}=.12$, the group by T2 performance interaction, $F(1,24)=0.01, p=.97, \eta_{\mathrm{p}}{ }^{2}=.00$, and the group by $\mathrm{T} 2$ performance by target context interaction were all non-significant, $F(1,24)=0.41, p=.53, \eta_{\mathrm{p}}{ }^{2}=.02$. Therefore, contrary to expectation there was no difference between the recall and recognition groups in the size of the semantic priming effect for T3 accuracy.

There was a significant main effect of target context, $F(1,24)=24.88, p<.001, \eta_{\mathrm{p}}{ }^{2}=.51$, and of T2 performance, $F(1,24)=125.94, p<.001, \eta_{\mathrm{p}}{ }^{2}=.81$. The interaction between T2 performance and target context was significant, $F(1,24)=25.22, p<.001, \eta_{\mathrm{p}}{ }^{2}=.51$. Simple effects analyses examined the priming effect (related vs. unrelated difference) within each of the T2 performance conditions. There was a significant priming effect when T2 was correct, $F(1,24)=29.76, p<.001, \eta_{\mathrm{p}}{ }^{2}=.55$ (Related $M=67.50 \%, S E=4.20$, Unrelated $M$ $=58.84 \%, S E=4.85)$ but not when T2 was incorrect, $F(1,24)=2.60, p=.120, \eta_{\mathrm{p}}{ }^{2}=.10$ (Related $M=6.94 \%$, $S E=0.77$, Unrelated $M=8.12 \%, S E=1.08$ ). From Table 2 it is evident that T3 accuracy was higher for T2-T3 related pairs than for unrelated T2-T3 pairs when T2 was correct and this priming effect was evident in both the recall and recognition tasks.

Table 2. Mean percent correct for T3 (SD) for Experiment 1 and 2 for the related and unrelated T2-T3 condition with $\mathrm{T} 2$ correct and $\mathrm{T} 2$ incorrect for the recall and recognition group

\begin{tabular}{lllll}
\hline & \multicolumn{2}{c}{ Recall Group } & \multicolumn{2}{c}{ Recognition Group } \\
& T2-T3 Related & T2-T3 Unrelated & T2-T3 Related & T2-T3 Unrelated \\
T2 answer & Mean\% $(S D)$ & Mean \% $(S D)$ & Mean \% (SD) & Mean \% (SD) \\
\hline Experiment 1 & & & & \\
T2 Correct & $70.82(15.87)$ & $60.07(21.02)$ & $64.34(26.44)$ & $57.62(28.34)$ \\
T2 Incorrect & $9.34(4.71)$ & $9.77(6.61)$ & $4.55(2.68)$ & $6.46(3.67)$ \\
\hline Experiment 2 & & & & \\
T2 Correct & $43.33(22.35)$ & $34.40(20.65)$ & $44.76(29.12)$ & $36.35(28.00)$ \\
T2 Incorrect & $14.69(8.57)$ & $15.01(9.16)$ & $7.68(4.87)$ & $7.39(4.51)$ \\
\hline
\end{tabular}

Note. Exp. $1 \mathrm{~N}=14$ recall group; $\mathrm{N}=12$ recognition group. Exp. $2 \mathrm{~N}=13$ recall group; $\mathrm{N}=13$ recognition group.

The priming effect in both the recall and recognition tasks when T2 was correctly identified is consistent with previous two-target attentional blink studies where T2 accuracy is higher if it is preceded by a related target (Maki, Frigen et al., 1997; Murphy \& Hunt, 2013; Nyawata \& Murphy 2013). Contrary to Shapiro, Driver et al. (1997), this experiment did not find semantic priming when T2 was missed. This failure to replicate the results of this previous study will be further investigated in Experiment 2.

\section{Experiment 2}

The results of Experiment 1 suggest that the priming observed by Shapiro, Driver et al. (1997) was not affected by target repetition at the response production stage as the magnitude of the priming effects for the recall and recognition tasks was not significantly different. In contrast to Shapiro, Driver, et al. (1997), Experiment 1 did not show priming when T2 was not identified (i.e., when T2 underwent an attentional blink). Experiment 1 presented each word for $70 \mathrm{msec}$ followed by a $20 \mathrm{msec}$ blank interval, which differs from the display times used by Shapiro, Driver et al. (1997) (15 msec word display time and $75 \mathrm{msec}$ blank interval). Although the display times used here were based on a pilot study that produced task accuracy similar to these researchers, it is possible that the stimulus display differences might have affected the priming effects in the RSVP task. Therefore, Experiment 2 used the same display times as Shapiro, Driver et al. (1997) to examine priming effects in a three-target RSVP task for recall and recognition response modalities. This would determine if the lack of $\mathrm{T} 3$ priming effect differences for the recall and recognition groups and only finding priming when $\mathrm{T} 2$ was reported were linked to the stimulus display durations. If the priming effects were affected by target repetition then there should be greater priming for the recall than recognition group in the current experiment. Additionally, if the longer stimulus times reduced the T3 priming effect when T2 was missed (blinked) then T3 priming should 
occur for missed $\mathrm{T} 2$ targets in this experiment.

\subsection{Method}

\subsubsection{Participants}

Participants were 26 first-year psychology students (19 females) aged between 17 and 50 years $(M=23.2$ years, $S D=7.12$ ). None of the participants had completed Experiment 1. Other participant characteristics were as reported in Experiment 1.

\subsubsection{Trial Structure, Tasks and Procedure}

The tasks and procedures were identical to that used in Experiment 1, except as indicated here. Each trial was composed of an RSVP stream of words where each word appeared on the screen for $15 \mathrm{msec}$, with a $75 \mathrm{msec}$ blank interval between each word. These stimulus display durations were the same as those used by Shapiro, Driver et al. (1997).

\subsection{Results and Discussion}

The same analysis was used for T1 and T3 accuracy as Experiment 1. T1 accuracy did not differ between the two response groups, $F(1,24)=0.43, p=.52, \eta_{\mathrm{p}}{ }^{2}=.02$, or the T2-T3 context (related vs. unrelated), $F(1,24)=0.31$, $p=.58, \eta_{\mathrm{p}}{ }^{2}=.01$. The interaction between group and target context was not significant, $F(1,24)=0.44, p=.52$, $\eta_{\mathrm{p}}{ }^{2}=.02$. Therefore, T1 accuracy was the same for related and unrelated T2-T3 contexts for the recall and recognition groups. Table 1 presents the relevant descriptive statistics for the T1 data for Experiment 2.

For T3 accuracy on trials where T1 was correct, there was no evidence of response modality affecting T3 accuracy as the main effect of response group, $F(1,24)=0.34, p=.55, \eta_{\mathrm{p}}{ }^{2}=.02$, the group by $\mathrm{T} 2$ performance interaction, $F(1,24)=0.71, p=.41, \eta_{\mathrm{p}}{ }^{2}=.03$, the group by T2-T3 context interaction $F(1,24)=0.00, p=.98$, $\eta_{\mathrm{p}}{ }^{2}=.00$ and the group by T2 performance by T2-T3 context interaction were all non-significant, $F(1,24)=0.03$, $p=.86, \eta_{\mathrm{p}}^{2}=.001$. Therefore performance in both the recall and recognition groups did not differ.

There was a significant main effect of target context $F(1,24)=16.40, p<.001, \eta_{\mathrm{p}}{ }^{2}=.41$ and of T2 performance, $F(1,24)=28.63, p<.001, \eta_{\mathrm{p}}{ }^{2}=.54$. The interaction between $\mathrm{T} 2$ performance and target context was significant, $F(1,24)=7.89, p=.010, \eta_{p}{ }^{2}=.25$. Simple effects analyses examined the priming effect within the T2 correct and incorrect conditions separately. This analysis revealed a significant T3 priming effect when T2 was correct, $F(1,24)=12.38, p=.002, \eta_{\mathrm{p}}{ }^{2}=.34$, (Related $M=44.04 \%, S E=5.09$; Unrelated $M=35.37 \%, S E=4.82$ ) but not when T2 was incorrect, $F(1,24)=0.00, p=.99, \eta_{\mathrm{p}}{ }^{2}=.00$, (Related $M=11.19 \%, S E=1.37$, Unrelated $M=$ $11.20 \%, S E=1.42$ ) From Table 2 it is evident that for both the recall and recognition groups, T3 accuracy was higher for related than unrelated T2-T3 pairs only when $\mathrm{T} 2$ was correct.

This experiment revealed semantic priming for both the recall and recognition groups when $\mathrm{T} 2$ was correctly identified. This replicates the effect reported by Shapiro, Driver et al. (1997) and is consistent with the priming observed in two-target RSVP studies (e.g., Maki, Frigen et al., 1997; Murphy \& Hunt, 2013; Nyawata \& Murphy, 2013). However, in contrast to Shapiro, Driver et al. (1997) and this study's prediction, there was no priming when T2 was incorrect. This was the same result as for Experiment 1 which used longer word display times. While this result differs from Shapiro, Driver et al. (1997), in their study the magnitude of the semantic priming effect was much smaller when T2 was missed compared to when T2 was reported. Moreover, the absence of priming effects in a three-target RSVP task when T2 has been missed is consistent with the outcomes of other studies (e.g., Peressotti, Pesciarelli, Mulatti, \& Dell'Acqua, 2012; Rolke et al., 2001).

\section{General Discussion}

This study sought to replicate the priming effects reported by Shapiro, Driver, et al (1997) and determine if target repetition at the response stage impacted on the magnitude of the semantic priming effects. Both Experiment 1 and 2 showed semantic priming for $\mathrm{T} 3$ when it was preceded by a related T2 compared to when $\mathrm{T} 2$ was unrelated to T3. However, priming was evident when T2 was correctly reported but not when T2 was missed which partially replicates the outcomes of Shapiro, Driver et al. (1997). The absence of priming for T3 when T2 was not reported is consistent with other three-target RSVP studies (e.g., Peressotti et al., 2012; Rolke et al., 2001). Repetition of targets at the response stage did not impact on performance in either experiment as the priming effects were of equivalent size for both task groups when both T2 and T3 were reported and no priming was evident when $\mathrm{T} 2$ was not reported.

The results of this study suggest that when $\mathrm{T} 2$ was missed, any context created by $\mathrm{T} 2$ in the related condition was insufficient to prime T3 accuracy. This suggests that meaning is not sufficiently extracted from words that are missed or incorrectly identified during the attentional blink period, and consequently this does not prime 
report of another target word. Therefore, a target must be consciously identified during the attentional blink period to produce a priming effect. This outcome is consistent with the priming effects observed in two-target RSVP tasks when both T1 and T2 were correctly reported (e.g., Maki, Frigen et al., 1997; Murphy \& Hunt, 2013). Future research in the two-target RSVP tasks could examine this issue by comparing the T2 accuracy for related and unrelated T1-T2 trials where T1 was not correctly reported.

The semantic priming effects for $\mathrm{T} 3$ were equivalent in both the recall and recognition groups indicating that target repetition at response did not affect RSVP task performance in either Experiment 1 or 2. These results were inconsistent with previous studies demonstrating a loss of meaning of repeated words (e.g., Smith, 1984; Smith \& Klein, 1990; Wertheimer \& Gillis, 1958) and the elimination of semantic priming effects due to extensive prime repetition (e.g., Neely et al., 1998; Pitzer \& Dagenbach, 2001). While these results indicate that priming is unaffected by target repetition at response, further research is required to examine the impact of target repetition during the actual RSVP task. In Shapiro, Driver et al.'s (1997) study the target words were repeated at the response stage and they were also presented 24 times each during the experimental trials. In this study, targets were presented 16 times each throughout the experimental trials. Therefore, it is possible that $\mathrm{T} 3$ priming was reduced by target repetition during the actual RSVP trials. Future research could examine this idea by compared T3 priming effects in an RSVP task where the targets are not repeated compared to a version of the task where the targets are repeated many times (e.g., 24 times as in Shapiro, Driver et al., 1997). By using this variation along with the recall response modality the impact of target repetition on $\mathrm{T} 3$ priming could be ascertained. If target repetition reduces the magnitude of priming effects then a smaller T3 priming effect should be apparent in the target repeat than target non-repeat versions of the RSVP task.

Chun and Potter (1995) proposed the two-stage model to account for the occurrence of the attentional blink and subsequent research (e.g., Murphy \& Hunt, 2013) has revealed that this approach can also account for priming in an RSVP task. In the two-stage model (Chun \& Potter, 1995), all RSVP items are checked for target features (e.g. color) and detected targets are consolidated into stage 2 to enable item report from short-term memory. When the two targets are separated by a short time period (e.g., 200 to $500 \mathrm{msec}$ ), the first target uses the consolidation resources and the next target must wait for the availability of stage 2 resources. Consequently, the second target receives interference from subsequent distractors and may be overwritten before it can be consolidated in short-term memory. This results in the attentional blink (e.g., impaired second target report).

These same principles would apply for a three-target RSVP task and can account for the outcomes of this study. During stage 1 processing, short lived representations are created for all three colored targets words. However, only targets words which have been consolidated into short-term memory would be available for subsequent report. In this study T3 accuracy was based on trials in which T1 was also correctly reported. Therefore both T1 and T3 must have been consolidated into short-term memory to be reported. In this study priming occurred when $\mathrm{T} 2$ was correct but not when it was missed or incorrect. This suggests that consolidation of T2 facilitates the report of T3 if T2 and T3 are related as opposed to being unrelated. Perhaps this occurs by allowing easier or faster consolidation of T2 because it shares a context with T3. That is, T3 is processed before it can be overwritten by distractors. When $\mathrm{T} 2$ is missed or incorrectly reported there is no difference in $\mathrm{T} 3$ accuracy between the related and unrelated T2-T3 contexts. This suggests that priming may only occur if an earlier target is able to create a context during stage 2 processing (consolidation into short-term memory). This explanation is consistent with previous studies demonstrating priming effects using the two-target RSVP tasks (e.g., Maki et al., 1997; Murphy \& Hunt, 2013).

The aims of this study were to replicate the semantic priming effects reported by Shapiro, Driver et al. (1997) in a three-target RSVP task and to examine the impact of target repetition during the response stage of this task. In two experiments a robust semantic priming effect was evident for both the recall and recognition groups when both T2 and T3 were correctly reported. These results indicate that target repetition at the response stage of an RSVP task does not impact on the magnitude of semantic priming effects. The lack of semantic priming when T3 was correctly reported but T2 was missed or incorrectly reported indicates that targets must be encoded into short-term memory to facilitate the report of other items within the RSVP stream. These results suggest that the locus of the semantic priming effect within a RSVP task may be linked to this consolidation process.

\section{References}

Bodner, G. E., \& Masson, M. E. J. (2001). Prime validity affects masked repetition priming: Episodic resource account of priming. Journal of Memory and Language, 45, 616-647. http://dx.doi.org/10.1006/jmla.2001.2791

Broadbent, D. E., \& Broadbent, M. H. P. (1987). From detection to identification: Response to multiple targets 
in rapid serial visual presentation. Perception and Psychophysics, 42, $105-113$. http://dx.doi.org/10.3758/BF03210498

Chun, M. M. (1997). Types and tokens in visual processing: A double dissociation between the attentional blink and repetition blindness. Journal of Experimental Psychology: Human Perception and Performance, 23, 738-755. http://dx.doi.org/10.1037/0096-1523.23.3.738

Chun, M. M., \& Potter, M. C. (1995). A two-stage model for multiple target detection in rapid serial visual presentation. Journal of Experimental Psychology: Human Perception and Performance, 21, 109-127. http://dx.doi.org/10.1037/0096-1523.21.1.109

Durgunoglu, A. Y. (1988). Repetition, semantic priming, and stimulus quality: Implications for the interactive-compensatory reading model. Journal of Experimental Psychology: Learning, Memory, and Cognition, 14, 590-603. http://dx.doi.org/10.1037/0278-7393.14.4.590

Dux, P. E., \& Harris, I. M. (2007). Viewpoint costs occur during consolidation: Evidence from the attentional blink. Cognition, 104, 47-58. http://dx.doi.org/10.1016/j.cognition.2006.05.004

Forster, K. I., \& Davis, C. (1984). Repetition priming and frequency attenuation in lexical access. Journal of Experimental Psychology: Learning, Memory, and Cognition, 10, 680-698. http://dx.doi.org/10.1037/0278-7393.10.4.680

Forster, K. I., \& Forster, J. C. (2003). DMDX: A windows display program with millisecond accuracy. Behavior Research Methods, Instruments, and Computers, 35, 116-124. http://dx.doi.org/10.3758/BF03195503

Ishihara, S. (1994). Ishihara's tests for colour-blindness (38th ed.). Tokyo, Japan: Kanehara and Company.

Juola, J. F., Duvuru, P., \& Peterson, M. S. (2000). Priming effects in attentional gating. Memory and Cognition, 28, 224-235. http://dx.doi.org/10.3758/BF03213802

Luck, S. J., Vogel, E. K., \& Shapiro, K. L. (1996). Word meanings can be accessed but not reported during the attentional blink. Nature, 383, 616-618. http://dx.doi.org/10.1038/383616a0

Luck, S. J., Woodman, G. F., \& Vogel, E. K. (1998). Event-related potential studies of attention. Trends in Cognitive Sciences, 4, 432-440. http://doi.org/10.1016/S1364-6613(00)01545-X

Maki, W. S., Bussard, G., Lopez, K., \& Digby, B. (2003). Sources of interference in the attentional blink: Target-distractor similarity revisited. Perception and Psychophysics, 65, 188-201. http://dx.doi.org/10.3758/BF03194794

Maki, W. S., Couture, T., Frigen, K., \& Lien, D. (1997). Sources of the attentional blink during rapid serial visual presentation: Perceptual interference and retrieval competition. Journal of Experimental Psychology: Human Perception and Performance, 23, 1393-1411. http://dx.doi.org/10.1037/0096-1523.23.5.1393

Maki, W. S., Frigen, K., \& Paulson, K. (1997). Associative priming by targets and distractors during rapid serial visual presentation: Does word meaning survive the attentional blink? Journal of Experimental Psychology: Human Perception and Performance, 23, 1014-1034. http://dx.doi.org/10.1037/0096-1523.23.4.1014

Martens, S., Wolters, G., \& van Raamsdonk, M. (2002). Blinks of the mind: Memory effects of attentional processes. Journal of Experimental Psychology: Human Perception and Performance, 28, 1275-1287. http://dx.doi.org/10.1037/0096-1523.28.6.1275

Murphy, K., \& Hunt, H. (2013). The time course of semantic and associative priming effects is different in an attentional blink task. Cognitive Processing, 14, 283-292. http://dx.doi.org/10.1007/s10339-013-0560-6

Meyer, D. E., \& Schvaneveldt, R. W. (1971). Facilitation of recognizing pairs of words: Evidence of a dependence between retrieval operations. Journal of Experimental Psychology, 90, $227-234$. http://dx.doi.org/10.1037/h0031564

Meyer, D. E., Schvaneveldt, R. W., \& Ruddy, M. G. (1975). Loci of contextual effects on visual word recognition. In Attention and performance $V$ (pp. 998-118).

Neely, J. H. (1991). Semantic priming effects in visual word recognition: A selective review of current findings and theories. In D. Besner, \& G. Humphreys (Eds.), Basic processes in reading: Visual word recognition (pp. 264-336). Hillsdale, NJ: Erlbaum.

Neely, J. H., VerWys, C. A., \& Kahan, T. A. (1998). Reading “glasses" will prime "vision”, but a pair of "glasses" will not. Memory and Cognition, 26, 34-39. http://dx.doi.org/10.3758/BF03211368

Nyawata, M. T., \& Murphy, K. (2013). Direction of association between targets in a RSVP task influences 
priming at very short but not long SOAs. Cognitive Processing, 14, 1-11. http://dx.doi.org/10.1007/s10339-012-0528-y

Peressotti, F., Pesciarelli, F., Mulatti, C., \& Dell'Acqua, R. (2012). Event-Related Potential Evidence for Two Functionally Dissociable Sources of Semantic Effects in the Attentional Blink. PLOS ONE, 7(11), http:// dx.doi.org/10.1371/journal.pone.0049099

Pitzer, K. D., \& Dagenbach, D. (2001). A constraint on eliminating semantic priming by repeating a prime. The American Journal of Psychology, 114, 43-53. http://dx.doi.org/10.2307/1423380

Raymond, J. E., Shapiro, K. L., \& Arnell, K. M. (1992). Temporary suppression of visual processing in an RSVP task: An attentional blink? Journal of Experimental Psychology: Human Perception and Performance, 18, 849-860. http://dx.doi.org/10.1037/0096-1523.18.3.849

Rolke, B., Heil, M., Streb, J., \& Hennighausen, E. (2001). Missed prime words within the attentional blink evoke an N400 semantic priming effect. Psychophysiology, 39, 165-174. http://dx.doi.org/10.1111/1469-8986.3820165

Rueckl, J. G. (1990). Similarity effects in word and pseudoword repetition priming. Journal of Experimental Psychology: Learning, Memory, and Cognition, 16, 374-391. http://dx.doi.org/10.1037/0278-7393.16.3.374

Schvaneveldt, R. W., \& Meyer, D. E. (1973). Retrieval and comparison processes in semantic memory. Attention and Performance IV, 395-409.

Shapiro, K. L., Arnell, K. M., \& Raymond, J. E. (1997). The attentional blink. Trends in Cognitive Science, 1, 291-296. http://dx.doi.org/10.1016/S1364-6613(97)01094-2

Shapiro, K., Driver, J., Ward, R., \& Sorensen, R. E. (1997). Priming from the attentional blink: A failure to extract visual tokens but not visual types. American Psychological Society, 8, 95-100. http://doi.org/10.1111/j.1467-9280.1997.tb00689.x

Shapiro, K. L., Raymond, J. E., \& Arnell, K. M. (1994). Attention to visual pattern information produces the attentional blink in rapid serial visual presentation. Journal of Experimental Psychology: Human, Perception, and Performance, 20, 357-371. http://dx.doi.org/10.1037/0096-1523.20.2.357

Smith, L. C. (1984). Semantic satiation affects category membership decision time but not lexical priming. Memory and Cognition, 12, 483-488. http://dx.doi.org/10.3758/BF03198310

Smith, L., \& Klein, R. (1990). Evidence for semantic satiation: Repeating a category slows subsequent semantic processing. Journal of Experimental Psychology: Human, Perception, and Performance, 16, 852-861. http://dx.doi.org/10.1037/0278-7393.16.5.852

Vogel, E. K., Luck, S. J., \& Shapiro, K. L. (1998). Electrophysiological evidence for a postperceptual locus of suppression during the attentional blink. Journal of Experimental Psychology: Human Perception and Performance, 24, 1656-1674. http://dx.doi.org/10.1037/0096-1523.24.6.1656

Wertheimer, M., \& Gillis, W. M. (1958). Satiation and the lapse of verbal meaning. Journal of General Psychology, 71, 412-415.

\section{Copyrights}

Copyright for this article is retained by the author(s), with first publication rights granted to the journal.

This is an open-access article distributed under the terms and conditions of the Creative Commons Attribution license (http://creativecommons.org/licenses/by/3.0/). 